\title{
Yeni 3,5-disübstitüe-2-pirazolin türevlerinin sentezi ve biyolojik aktivitelerinin incelenmesi
}

\author{
Nuran KAHRIMAN* \\ Karadeniz Teknik Üniversitesi, Fen Fakültesi, Kimya Bölümü, Trabzon, Türkiye \\ Geliș Tarihi (Received Date): 26.03.2019 \\ Kabul Tarihi (Accepted Date): 26.08.2019
}

\section{$\ddot{\mathbf{O} z}$}

Bu çalışmada elektronca zengin azot atomu içeren 5 üyeli heterosikliklerden biri olan pirazolin türevi 3 adet yeni bileşik kalkonlardan başlanarak sentezlendi. Pirazolinlerin sahip olduklart biyolojik ve farmakolojik özelliği sebebiyle bu bileşiklerin DPPH radikal süpürme ve fosfomolibdenyum indirgeyici güç (PRAP) aktiviteleri ile tirozinaz ve $\alpha$-glikozidaz enzim inhibisyon aktiviteleri araştırıld. Elde edilen veriler doğrultusunda $4\left(I C_{50}=16.68 \pm 0.19 \mu M\right)$ ve $6\left(I C_{50}=\mathbf{2 2 . 6 0} \pm \mathbf{0 . 8 3} \mu M\right)$ nolu bileşiklerin standart kojik asitten $\left(I C_{50}=35.41 \pm 0.19 \mu M\right)$ daha iyi tirozinaz inhibisyon aktiviteye sahip oldukları belirlendi. Bileşiklerin a-glukozidaz enzim inhibisyon aktiviteleri çok yüksek olmamakla birlikte $4\left(I C_{50}=134.24 \pm 2.51 \mu M\right)$ nolu bileşik en yüksek aktiviteyi gösterdi. Bileşiklerin antioksidan aktivite değerlerine bakıldığında ise 5 nolu bileşik en yüksek DPPH radikal süpürme (\%67.59 \pm 0.44) ve fosfomolibdenyum indirgeyici güç (PRAP, Abs $=0.815 \pm 0.009)$ aktivitesini sergiledi. Sonuç olarak bileşik yapılarında farklılık gösteren - $\mathrm{NH}_{2}$ grubunun bağlanma pozisyonu, bileşiklerin biyolojik özelliklerinde belirgin bir farklılĭga sebep olmuştur.

Anahtar kelimeler: Pirazolin, tirozinaz ve $\alpha$-glikozidaz inhibisyonu, DPPH ve PRAP antioksidan aktivite.

\section{Synthesis and biological activity investigation of new 3,5- disubstituted-2-pyrazoline derivatives}

\begin{abstract}
In this study 3 new pyrazolines, one of the electron-rich nitrogen containing heterocyclics, derivative compounds were synthesized starting from chalcones. Due to the biological and pharmacological properties of pyrazolines, DPPH radical
\end{abstract}

\footnotetext{
*Nuran KAHRIMAN, nuran_yayli@hotmail.com, http://orcid.org/0000-0001-9729-433X
} 
scavenging and phosphomolybdenum reducing power (PRAP) activities and tyrosinase and $\alpha$-glycosidase enzyme inhibition activities of these compounds were investigated . Based on the obtained results, it was determined that compounds $4\left(I C_{50}=16.68 \pm 0.19\right.$ $\mu M)$ and $6\left(I C_{50}=22.60 \pm 0.83 \mu M\right)$ had better tyrosinase inhibitory activities than standard kojic acid $\left(I C_{50}=35.41 \pm 0.19 \mu M\right)$. Although the $\alpha$-glucosidase enzyme inhibition activities of the compounds were not very high, compound $4\left(I C_{50}=134.24 \pm\right.$ $2.51 \mu \mathrm{M})$ showed the highest activity. When the antioxidant activity values of the compounds were examined, compound 5 showed the highest DPPH radical scavenging $(67.59 \pm 0.44 \%)$ and phosphomolybdenum reducing power $(P R A P, A b s=0.815 \pm$ $0.009)$ activities. As a result, the binding position of the $-\mathrm{NH}_{2}$ group, which differed in the compound structures, also caused a significant difference in the biological properties of the compounds..

Keywords: Pyrazoline, tyrosinase and $\alpha$-glycosidase inhibition, DPPH and PRAP antioxidant activity.

\section{Giriş}

Tirozinaz, tıpta ve kozmetikte oldukça önemli bir enzim olup melanin sentezinin aşırı olmasından oluşan cilt lekesi gibi hiperpigmentasyon problemlerinde önemli role sahiptir [1]. Melaninin aşırı sentezi mantar, meyve ve sebzede meydana gelen enzimatik esmerleşmenin de sebebi olup bu durum ürünlerin ticari değerini düşürmekte ve zirai alanda da büyük sıkıntı oluşturmaktadır [2]. Tirozinaz inhibitörü bileşikler ise deride, bitkilerde pigmentasyonu önleyici ve güneş yanıkları sonrası deri beyazlatıcı etkilerinden dolayı üzerinde uzun yıllardır çalışılan konulardan biri olup güvenilir ve etkili tirosinaz inhibitörleri tıp, kimya, biyoloji, zirai bilimler ve farmakoloji alanında bir çok bilim adamının ilgisini çekmiştir [3-4]. Bir başka enzimatik problem olan Diabetes mellitus; ise günümüzde, sıklığı ve yarattığı sorunlar nedeniyle tüm dünyada önemi gittikçe artan bir sağlı sorunudur [5]. $\alpha$-Glukozidaz enziminin yol açtığı Diabetes mellitus tedavisinde ise inhibitör ajanlar iş görmektedir. Bu sebeple birçok bilim adamı yeni inhibitörlerin keşfinde ve sentezinde önemli çalışmalar yapmaktadırlar [6]. Özellikle elektronca zengin azot atomu içeren heterosiklik bileşikler enzim inhibisyonunun da yer aldığı geniş biyolojik özellikleri ile son yılların ilgi odağı haline gelmiştir [6-7].

Elektronca zengin azot atomu içeren heterosiklikler çeşitli biyolojik aktivitelerde önemli role sahiptirler. Bir heterosiklik sistem olan pirazolin türevi bileşikler, kalkonlardan başlanılarak sentezlenebilen [8-11], 1 ve 2 pozisyonunda azot içeren 5 üyeli heterosiklik sistemler olup biyolojik olarak büyük öneme sahiptirler [12]. Bu bileşikler doğada alkaloid, vitamin, pigment, hayvan ve bitki hücre bileşenleri olarak değişik formlarda doğada yaygın bir şekilde bulunmaktadırlar [13]. Pirazolin (dihidropirazol) halka sistemi 3 farklı tautomerik forma sahip olup [14] bu çalışmada $\Delta^{2}$-pirazolin (2) türevlerinin 3,5-disübstitüe türevleri sentezlenmiştir. 


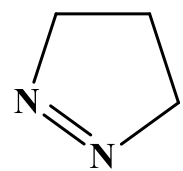

1

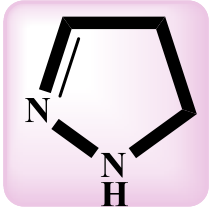

2<smiles>C1=CNNC1</smiles>

3

Şekil 1. Pirazolinin tautomerik formları [14].

Bu bileşikler bir çok ilacın temel yapısını oluşturmaktadırlar [9, 12, 15]. Göstermiş oldukları antikanser [16-18], antibakteriyal [19], antifungal [9], antiinflamatuvar [20], antidepresan [9,12], ziraii ilaç [10], antidiabetik [21], analjezik [19-20], antitüberkülar [12], antiviral [12], antioksidan [15], MaO [12], topoizomeraz I \& II [22], tirosinaz [17, 23] inhibitörü vb. özellikleri farmakoloji, tıp ve ziraatte bu bileşikleri öne çıkarmıştır.<smiles>Cc1ccc(C2=NN(c3ccccc3)C(c3ccc(C)cc3)C2)cc1</smiles>

Analjezik [12]<smiles>COc1cc(C2CC(c3cc4ccccc4oc3=O)=NN2c2nc(-c3ccc(Br)cc3)cs2)ccc1OCc1ccccc1</smiles>

Mantar tirosinaz inhibitörü [23]<smiles>[R]c1cccc(C2=NNC(c3cc(Cc4ccc(O)c(C5CC(c6ccccc6)=NN5)c4)ccc3O)C2)c1</smiles>

$\mathrm{R}=\mathrm{Cl}, \mathrm{CH}_{3}$; Anti-kanser [15]<smiles>COc1ccc(-c2c[nH]nc2C(=O)c2c(O)cc(C)c(Cl)c2C)cc1</smiles>

Antifungal [15]

Şekil 2. Literatürde bulunan bazı biyoaktif pirazolin türevleri.

Fenazon/ amidopiren/ metampiron (analjezik ve antipiretik), azolid/ tandearil (antiinflamatuvar), indoksakarb (insektisit) ve anturan/allopurinol (ürikozürik) molekülleri ilaç olarak kullanılan sayısız biyoaktif pirazolin sınıfı bileşiklerden sadece bir kaçıdır [24].

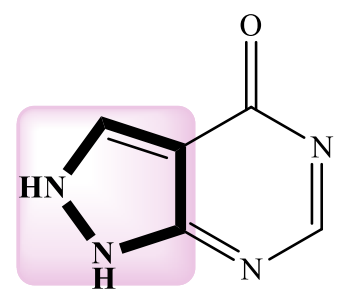

Allopurinol (ürikozürik)

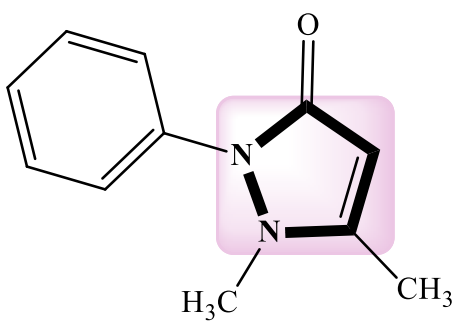

Fenazon (analjezik ve antipiretik)

Şekil 3. Pirazolin halka sistemi içeren bazı ilaçlar. 
Literatürde, pirazolin sınıfı bileşiklerin değişik şekilde sentezleri mevcuttur [9, 10, 24]. Kalkonlar da, bu bileşiklerin sentezinde önemli çıkış bileşikleridir [9-11]. Kalkonlar, 1,3-diaril-2-propen-1-on iskeletini içerdikleri için birçok bileşik sınıfının sentezinde çıkış olarak kullanılan özellikle de 5, 6 ve 7 üyeli heterosiklik bileşiklerin sentezin de uygun ara ürünlerdir [9-10].

Bu çalışmada amino sübstitüe asetofenonlar ve hidroksi sübstitüe benzaldehitten yola çıkarak sentezlenen kalkonların hidrazinle Michael katılması üzerinden verdikleri halkalaşma reaksiyonları sonucu pirazolin bileşiklerinin (4-6) sentezi gerçekleştirilmiş ve bu bileşiklerin. DPPH radikal süpürme ve fosfomolibdenyum indirgeyici güç (PRAP) aktiviteleri ile tirozinaz ve $\alpha$-glikozidaz enzim inhibisyon aktiviteleri araştırılmıştır.

\section{Deneysel çalışmalar}

\section{1. Çözücüler ve kimyasallar}

Bileşiklerin sentezinde kullanılan 2'/3'/4'-aminoasetofenon, 3-hidroksibenzaldehit, sodyum hidroksit, hidrazin monohidrat ve asetik asit Merck ve Sigma-Aldrich marka olup analitik saflıktadır. Sentezde, saflaştırmada ve diğer enstrümental cihazlarda analiz yapılırken kullanılan etanol, kloroform, dietil eter, etil asetat, hegzan, aseton gibi çözücüler Merck ve Sigma-Aldrich marka olup analitik saflıktadır. Yine NMR alınırken kullanılan DMSO- $\mathrm{d}_{6}$ da Sigma-Aldrich marka olup \%99.8 saflıktadır. Antioksidan, tirosinaz ve $\alpha$-glukozidaz enzimlerinin aktivite ölçümleri için kullanılan akarboz, 2,2-difenil-1-pikrilhidrazil (DPPH), gallik asit (GA), etanol, trizma-baz, etilendiamintetraasetik asit fosfomolibdik asit, tirosinaz, L-DOPA, kojik asit, tirosinaz enzimi (E.C.1.14.18.1), $\alpha$-glukozidaz enzimi (E.C.3.2.1.20) kimyasalları da SigmaAldrich (St. Louis, MO, USA)'dan satın alınmıştır.

\subsection{Enstrümentasyon}

Sentezlenen bileşiklerin NMR spektrumları Bruker marka $400 \mathrm{MHz}$ NMR cihazında alınmıştır. IR spektrumları Perkin-Elmer 1600 FT-IR (4000-400 $\left.\mathrm{cm}^{-1}\right)$ spektrofotometre cihazı, kütle spektrumları Micromass Quattro LC-MS/MS spektrofotometre cihazı kullanılarak alınmıştır. Reaksiyon ilerleyişinde ince tabaka kromatografisi kullanılmış (ITK), saflaştırma aşamasında ise kristallendirme yapılmıştır. Erime noktaları Stuart marka SMP10 model erime noktası tayin cihazı kullanılarak belirlenmiştir. ${ }^{1} \mathrm{H}-\mathrm{NMR}$ spektrumları TMS pikine göre, APT NMR spektrumları ise DMSO-d 6 ( $\delta 39.7$ ppm) çözücü pikine göre ayarlanmıştır. Kütle spektrumları elektron sprey (ES) yöntemi kullanılarak alınmıştır. İnce tabaka kromatografisinde (ITTK) normal faz silikajel $60 \mathrm{~F}_{254}$ kullanılmıştır. İnce tabakadaki ayrılmaların kontrolü için kabin içinde bulunan $254 \mathrm{~nm}$ ' lik UV lamba kullanılmıştır. NMR spektrumları alınırken çözücü olarak DMSO-d 6 kullanılmıştır. Numuneler kuartz NMR tüplerine konularak ölçümler yapılmıştır. FT-IR spektrumları katı numuneler üzerinden ve $400-4000 \mathrm{~cm}^{-1}$ bölgesinde ölçümler yapılarak alınmıştır.

\subsection{Bileşiklerin sentezi}

3,5-Disübstitüe-2-pirazolin bileşiklerinin sentezlenmesinde ilk olarak çıkış bileşikleri olan amino ve hidroksi sübstitüe kalkon bileşiklerinin (1-3) sentezi Claisen-Schmidt kondenzasyonu kullanılarak gerçekleştirildi. Bu bileşikler bilinen bileşikler olup detaylı sentezleri literatürde mevcuttur [19]. 
3,5-disübstitüe-2-pirazolin bileşiklerinin sentezi için ise elde edilen kalkon bileşiklerinden (1-3) ayrı ayrı alınan 10 mmol'lük kısımlar $20 \mathrm{~mL}$ kuru etanolde çözülerek üzerine stokiyometrik miktarda hidrazin monohidrat ve $2 \mathrm{~mL}$ glasiyel asetik asit ilave edilmiştir. Reaksiyon ilerleyişi İTK ile kontrol edilip tamamlanan reaksiyonlar bir gece kendi halinde bekletilmiştir. Oluşan kristaller süzülüp soğuk etanolle yıkandıktan sonra kurutulmuş, İTK ile saflık kontrolü yapılmış ve spektroskopik yöntemlerle yapısı aydınlatılmıştır. Tüm spektroskopik veriler hedeflenen yapıları doğrular niteliktedir.

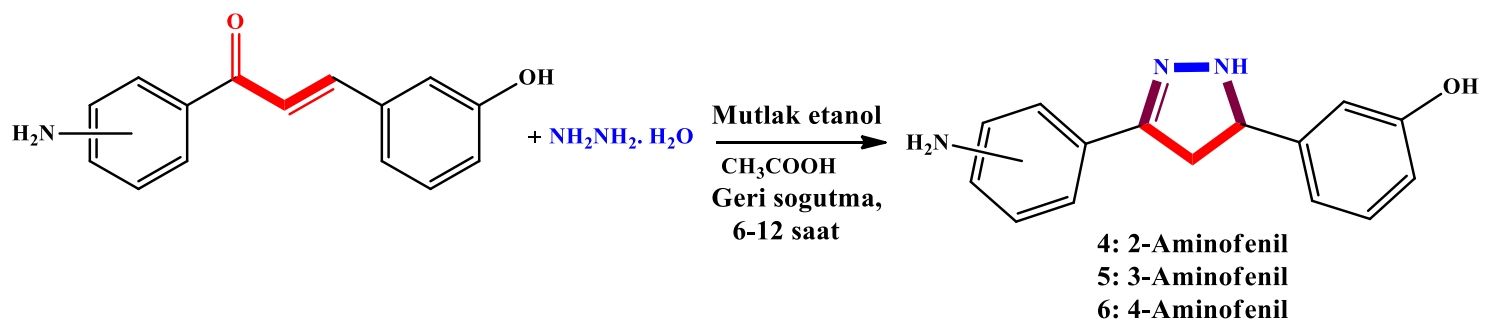

Şekil 4. 4-6 Nolu bileşiklere (pirazolinler) ait sentez şeması.

\subsection{Antioksidan yöntemler}

\subsubsection{DPPH Radikal süpürme aktivitesinin belirlenmesi}

Numunelerin 2,2-difenil-1-pikril hidrazil (DPPH) radikal süpürme aktivitesi, Blios yöntemine göre gerçekleştirilmiştir [25]. Kısaca, 0.4 mM DPPH'ın metanoldeki çözeltisi üzerine bileşikler ilave edildi. Karanlık bir ortamda oda sıcaklığında 30 dakika inkübasyonun ardından 517 nm'de absorbans ölçülmüştür (Aörnek). $0.4 \mathrm{mM} 1 \mathrm{~mL} \mathrm{DPPH}$ metanoldeki çözeltisinin $517 \mathrm{~nm}$ 'deki absorbansı ölçülmüştür $\left(\mathrm{A}_{\text {kontrol }}\right)$. Standart olarak gallik asit (GA) kullanılmıştır. DPPH serbest radikal süpürme aktivitesi, DPPH radikallerinin inhibisyonu (\% I) şeklinde farklı konsantrasyonları için 1 numaralı formülden hesaplanmıştır. Tüm deneyler üç tekrarlı gerçekleştirilmiş ve standart sapması (SD) hesaplanmıştır.

$\%$ inhibisyon $=\frac{A_{k \ddot{o r}}-A_{\ddot{o} r n e k}}{\text { Aörnek }} \times 100$

Formül 1

\subsubsection{Fosfomolibdenyum indirgeyici antioksidan kapasite ölçümü (PRAP)}

Fosfomolibdenyum indirgeyici antioksidan kapasite ölçüm yöntemi \%10'luk fosfomolibdik asit kullanılarak hesaplandı ve standart bileşik olarak kuersetin kullanılmıştır [26]. İlk olarak etanol içerisinde \%10'luk fosfomolibdenyum çözeltisi hazırlandı ve son hacim $1 \mathrm{~mL}$ olacak şekilde örnekler çözeltiye ilaveye edilmiştir. Karışım $80{ }^{\circ} \mathrm{C}$ 'de 30 dakika inkübe edilmiştir. $\mathrm{Bu}$ süre sonunda karışımların absorbansları $600 \mathrm{~nm}$ 'de okundu ve kuersetin ile karşılaştırılarak fosfomolibdenyum indirgeyici antioksidan kapasitesi belirlenmiştir. Tüm deneyler üç tekrarlı gerçekleştirilmiş ve standart sapması (SD) hesaplanmıştır.

\subsection{Enzim inhibisyonlart}

\subsubsection{Tirosinaz inhibisyonu}

Bileşiklerin tirosinaz inhibisyon kapasitesi, Masuda ve ark. tarafından geliştirilen, 3,4dihidroksi-L-fenilalanin'in (L-DOPA) substrat olarak kullanıldığı modifiye dopakrom yöntemi ile spektrofotometrik olarak tayin edilecektir [27]. Standart olarak alfa-kojik asit'in kulanıldığı deneyler, 96 kuyucuklu mikroplak kullanılarak mikroplak okuyucuda 
(Uv-Spektrofotometre, Multiskan Go) gerçekleştirilmiştir. Deney protokolüne göre; hazırlanan bileşiklerin her birinden $20 \mu \mathrm{L}$ alınarak, daha önceden her birine $100 \mu \mathrm{L}$ fosfat tamponu ( $\mathrm{pH}$ 6.8) eklenmiş kuyucuklara ilave edilmiştir. Bunun üzerine $20 \mu \mathrm{L}$ $250 \mathrm{U} / \mathrm{mL}$ tirosinaz enzimi ve $20 \mu \mathrm{L}$ L-DOPA çözeltisi ilave edilmiştir. 10 dakika inkübasyon süresinden sonra, mikroplaklar spektrofotometre cihazına yerleştirilerek, örnekler ve kontrolün absorbansları $475 \mathrm{~nm}$ dalga boyunda okunadu ve tirosinaz inhibisyonları Formül 1'e göre hesaplanmıştır. Tüm deneyler üç tekrarlı gerçekleştirilmiş ve standart sapması (SD) hesaplanmıştır.

\subsection{2. $\alpha$-Glukozidaz inhibisyonu}

Bileşiklerin $\alpha$-glukozidaz inhibisyon özellikleri literatürde bulunan yöntemlerde küçük modifikasyonlar gerçekleştirilerek incelenmiştir [28]. Akarboz standart bileşik olarak kullanılmıştır. Kısaca $100 \mu \mathrm{L} 0.5 \mathrm{U} / \mathrm{mL} \alpha$-glukozidaz enzimi ve bileşiklerin çeşitli konsantrasyonlarını içeren mikroplakalar 15 dakika oda sıcaklığında inkübasyona bırakılmıştır. Daha sonra substrat çözeltisi olarak $50 \mu \mathrm{L} 5 \mathrm{mM}$ 4-nitrofenil- $\alpha$-Dglukopiranozit ilave edilmiştir. 15 dakika inkübasyona bıraktıktan mikroplaka okuyucu yardımıyla $405 \mathrm{~nm}$ 'de absorbansı ölçüldükten sonra bileşiklerin formül 1 kullanılarak $\mathrm{IC}_{50}$ değeri hesaplanmıştır.

\section{Bulgular}

Yapılan çalışmanın ilk kısmında 6 adet bileşik sentezlenmiş olup bunların 3 tanesi (4-6) literatürde bulunmayan yeni 3,5-disübstitüe-2-pirazolin türevi bileşiklerdir. $\mathrm{Bu}$ bileşiklerin yapıları ve adlandırılmaları (Tablo 1), verim, erime Noktası, Rf, NMR, FTIR ve LC-MS/MS değerleri aşağıda verilmiştir.

Tablo 1. Sentezlenen 4-6 nolu 3,5-disübstitüe-2-pirazolin türevlerinin yapıları ve IUPAC adlandirmaları.

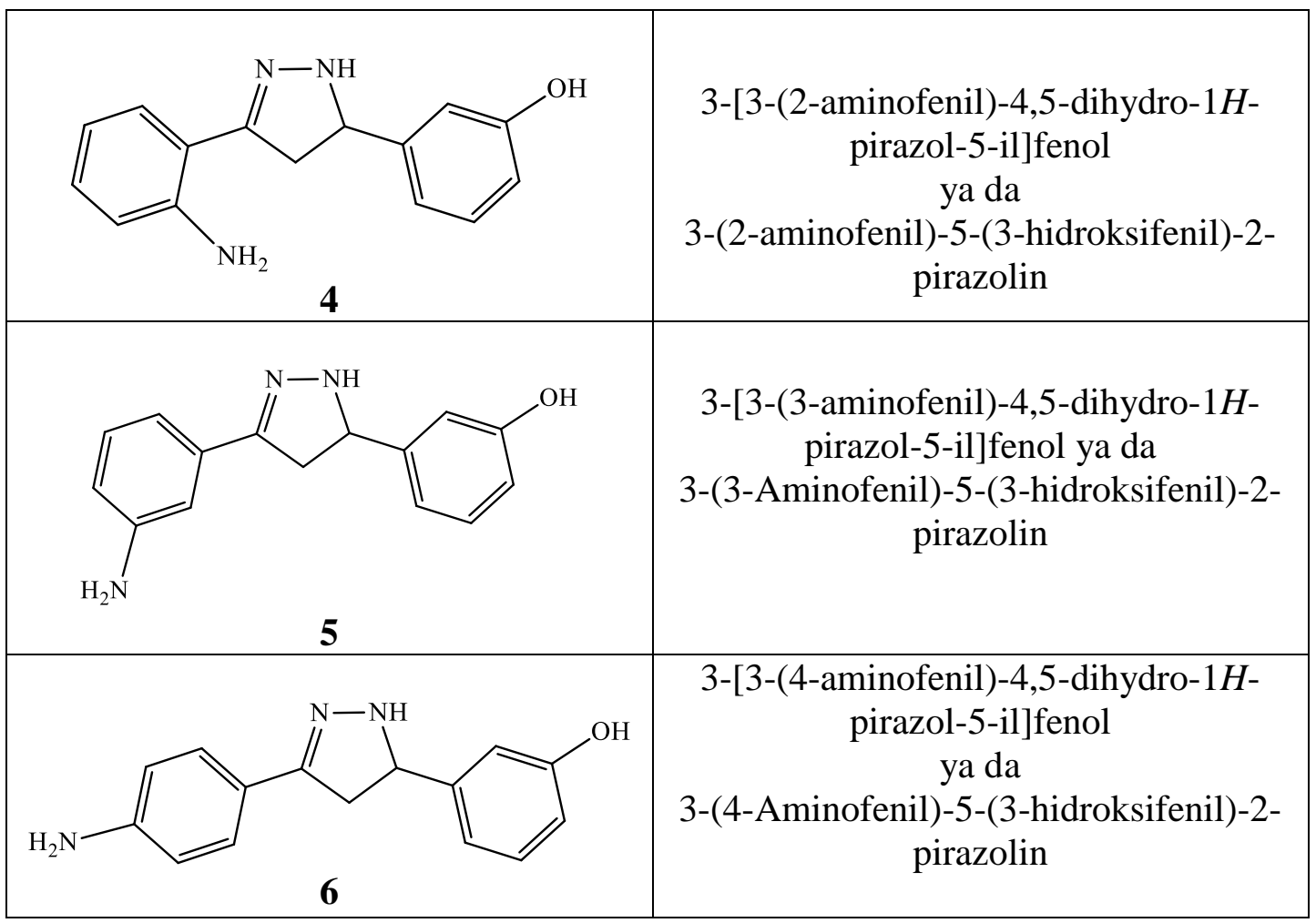


4.1. Sentezlenen Bileşiklere Ait Verim, Erime Noktası, Rf, NMR, FT-IR ve LC-MS/MS Değerleri

\subsubsection{3-[3-(2-aminofenil)-4,5-dihydro-1H-pirazol-5-il]fenol (4)}

Renk: Açık sarı katı; Verim (\%): 83; Erime noktası ( ${ }^{\circ}$ C): 196-198; Rf: 0.75 (Eter-etil asetat: $1: 1)$.

FT-IR (cm $\left.{ }^{-1}\right): 3671(\mathrm{O}-\mathrm{H}), 3471(\mathrm{~N}-\mathrm{H}), 3384$ ve $3326\left(\mathrm{NH}_{2}\right), 3061(\mathrm{Ar}-\mathrm{H})$, 2979-2879 (Alp.C-H), $1621(\mathrm{C}=\mathrm{N}), 1594(\mathrm{C}=\mathrm{C}), 1260(\mathrm{C}-\mathrm{N})$.

${ }^{1} \mathrm{H}-N M R$ (400 MHz, CD3OD/DMSO-d6, ppm): $\delta=2.74-2.67$ (dd, $J=16.0 / 8.0 \mathrm{~Hz}, 1 \mathrm{H}$, $\left.\mathrm{H}-4_{\mathrm{A}}\right) ; \delta=3.33-3.26\left(\mathrm{dd}, J=16.0 / 8.0 \mathrm{~Hz}, \mathrm{H}-4_{\mathrm{B}}\right) ; \delta=4.64$ (dd, $\left.J=10.0 / 8.0 \mathrm{~Hz}, 1 \mathrm{H}, \mathrm{H}-5\right)$; $\delta=6.75\left(\mathrm{~s}, 1 \mathrm{H}, \mathrm{H}-2^{\prime}\right) ; \delta=6.63\left(\mathrm{~d}, 8.0 \mathrm{~Hz}, 1 \mathrm{H}, \mathrm{H}-4^{\prime}\right) ; \delta=7.12\left(\mathrm{t}, J=8.0 \mathrm{~Hz}, 1 \mathrm{H}, \mathrm{H}-5^{\prime}\right) ; \delta=$ $6.73\left(\mathrm{~d}, J=8.0 \mathrm{~Hz}, 1 \mathrm{H}, \mathrm{H}-6^{\prime}\right) ; \delta=6.70(\mathrm{~d}, J=8.0 \mathrm{~Hz}, 1 \mathrm{H}, \mathrm{H}-3 ") ; \delta=7.32$ (t, $7.8 \mathrm{~Hz}, 1 \mathrm{H}$, H-4"); $\delta=6.60$ (t, J=7.8 Hz, 1H, H-5"); $\delta=7.12$ (d, $J=7.8 \mathrm{~Hz}, 1 \mathrm{H}, \mathrm{H}-6 ")$.

${ }^{13}$ C-NMR (100 MHz, DMSO-d6, ppm): 151.5 (C-3), 42.1 (C-4), 61.9 (C-5), 144.7 (C1'), 113.3 (C-2'), 157.4 (C-3'), 114.7 (C-4'), 129.3 (C-5'), 117.3 (C-6'), 114.3 (C-1"), 147.0 (C-2"), 114.0 (C-3"), 128.5 (C-4"), 114.8 (C-5"), 128.4 (C-6").

Pozitif LC-MS/MS m/z (\%): 253 (100) [M] $]^{+}, 239(55)\left[\mathrm{M}-\mathrm{NH}_{2}\right]^{+}$.

\subsection{2. (3-[3-(3-aminofenil)-4,5-dihydro-1H-pirazol-5-il]fenol (5)}

Renk: Beyaz amorf katı; Verim (\%): 66; Erime noktası ( ${ }^{\circ}$ C): 192-194; Rf: 0.70 (Eteretil asetat: $1: 1)$.

FT-IR $\left(\mathbf{c m}^{-1}\right)$ : $3671(\mathrm{O}-\mathrm{H}), 3470(\mathrm{~N}-\mathrm{H}), 3384$ ve $3326\left(\mathrm{NH}_{2}\right), 3055(\mathrm{Ar}-\mathrm{H}), 2988-2901$ (Alp.C-H), $1634(\mathrm{C}=\mathrm{N}), 1593(\mathrm{C}=\mathrm{C}), 1256(\mathrm{C}-\mathrm{N})$.

${ }^{1} \mathrm{H}-\mathrm{NMR}$ (400 MHz, CD3OD/DMSO-d6, ppm): $\delta=2.72-2.66(\mathrm{dd}, J=16.0 / 8.0 \mathrm{~Hz}, 1 \mathrm{H}$, $\mathrm{H}-4_{\mathrm{a}}$ ); $\delta=3.35-3.27$ (dd, $J=16.0 / 8.0 \mathrm{~Hz}, \mathrm{H}-4_{\mathrm{b}}$ ); $\delta=4.64$ (dd, $J=10.0 / 8.0 \mathrm{~Hz}, 1 \mathrm{H}, \mathrm{H}-5$ ); $\delta=6.78\left(\mathrm{~s}, 1 \mathrm{H}, \mathrm{H}-2^{\prime}\right) ; \delta=6.60\left(\mathrm{~d}, 8.0 \mathrm{~Hz}, 1 \mathrm{H}, \mathrm{H}-4^{\prime}\right) ; \delta=7.10\left(\mathrm{t}, J=8.0 \mathrm{~Hz}, 1 \mathrm{H}, \mathrm{H}-5^{\prime}\right) ; \delta=$ $6.74\left(\mathrm{~d}, J=8.0 \mathrm{~Hz}, 1 \mathrm{H}, \mathrm{H}-6^{\prime}\right) ; \delta=6.68\left(\mathrm{~s}, 1 \mathrm{H}, \mathrm{H}-2^{\prime \prime}\right) ; \delta=6.62\left(\mathrm{~d}, 7.8 \mathrm{~Hz}, 1 \mathrm{H}, \mathrm{H}-4^{\prime \prime}\right) ; \delta=$ 7.18 (t, $\left.J=7.8 \mathrm{~Hz}, 1 \mathrm{H}, \mathrm{H}-5^{\prime \prime}\right) ; \delta=7.22$ (d, $\left.J=7.8 \mathrm{~Hz}, 1 \mathrm{H}, \mathrm{H}-6 "\right)$.

${ }^{13}$ C-NMR (100 MHz, DMSO-d6, ppm): 149.3 (C-3), 40.8 (C-4), 63.3 (C-5), 144.8 (C1'), 110.9 (C-2'), 157.4 (C-3'), 113.2 (C-4'), 129.4 (C-5'), 114.3 (C-6'), 133.7 (C-1"), 113.8 (C-2"), 148.6 (C-3"), 114.1 (C-4"), 128.9 (C-5"), 117.2 (C-6").

Pozitif LC-MS/MS m/z (\%): 253 (100) [M] ${ }^{+}, 239(30)\left[{\left.\mathrm{M}-\mathrm{NH}_{2}\right]^{+} .}\right.$.

\subsubsection{3-[3-(4-aminofenil)-4,5-dihydro-1H-pirazol-5-il]fenol (6)}

Renk: Parlak beyaz kristal; Verim (\%): 88; Erime noktası ( $\left.{ }^{\circ} \mathbf{C}\right): 224-227$; Rf: 0.70 (Eter-etil asetat: 1:1).

FT-IR (cm $\left.{ }^{-1}\right): 3671(\mathrm{O}-\mathrm{H}), 3470(\mathrm{~N}-\mathrm{H}), 3382$ ve $3326\left(\mathrm{NH}_{2}\right), 3062(\mathrm{Ar}-\mathrm{H}), 2979-2879$ (Alp.C-H), $1619(\mathrm{C}=\mathrm{N}), 1588(\mathrm{C}=\mathrm{C}), 1259(\mathrm{C}-\mathrm{N})$.

${ }^{1}$ H-NMR (400 MHz, CD3OD/DMSO-d6, ppm): $\delta=2.72-2.66(\mathrm{dd}, J=16.0 / 8.0 \mathrm{~Hz}, 1 \mathrm{H}$, H-4a) $\delta=3.33-3.27$ (dd, $J=16.0 / 8.0 \mathrm{~Hz}, \mathrm{H}-4_{\mathrm{b}}$ ); $\delta=4.62$ (dd, $\left.J=10.0 / 8.0 \mathrm{~Hz}, 1 \mathrm{H}, \mathrm{H}-5\right)$; $\delta=6.77\left(\mathrm{~s}, 1 \mathrm{H}, \mathrm{H}-2^{\prime}\right) ; \delta=6.63\left(\mathrm{~d}, 8.0 \mathrm{~Hz}, 1 \mathrm{H}, \mathrm{H}-4^{\prime}\right) ; \delta=7.10\left(\mathrm{t}, J=8.0 \mathrm{~Hz}, 1 \mathrm{H}, \mathrm{H}-5^{\prime}\right) ; \delta=$ $6.76\left(\mathrm{~d}, J=8.0 \mathrm{~Hz}, 1 \mathrm{H}, \mathrm{H}-6^{\prime}\right) ; \delta=7.31$ (d, J=8.0 Hz, 2H, H-2"/6"); $\delta=6.54$ (d, $J=8.0 \mathrm{~Hz}$, 2H, H-3"/5").

${ }^{13}$ C-NMR (100 MHz, DMSO-d6, ppm): 150.3(C-3), 41.6 (C-4), 63.6 (C-5), 145.5 (C1'), 113.7 (C-2'), 157.9 (C-3'), 114.4 (C-4'), 129.8 (C-5'), 117.7 (C-6'), 121.4 (C-1"), 127.2 (C-2"/6"), 149.6 (C-4"), 114.0 (C-3"/5").

Pozitif LC-MS/MS m/z (\%): 253 (100) [M] ${ }^{+}$.

6 Nolu bileşiğe ait NMR ve FT-IR spektrumları Şekil 5-7'de verilmiştir. 
$1 \mathrm{H}$<smiles>Nc1ccc(C2CNC(c3cccc(O)c3)C2)cc1</smiles>

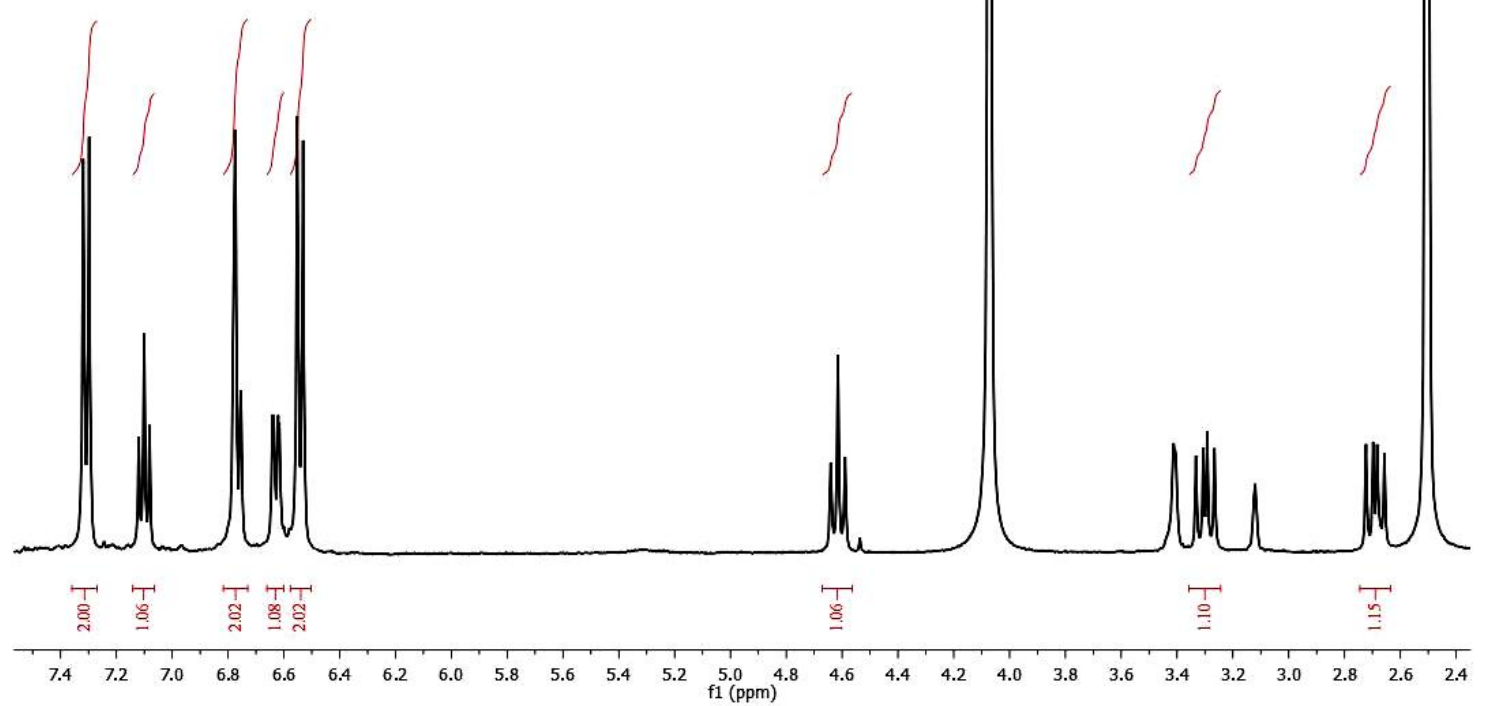

Şekil 5. 6 Nolu bileşiğin ${ }^{1} \mathrm{H}-\mathrm{NMR}$ spektrumu.

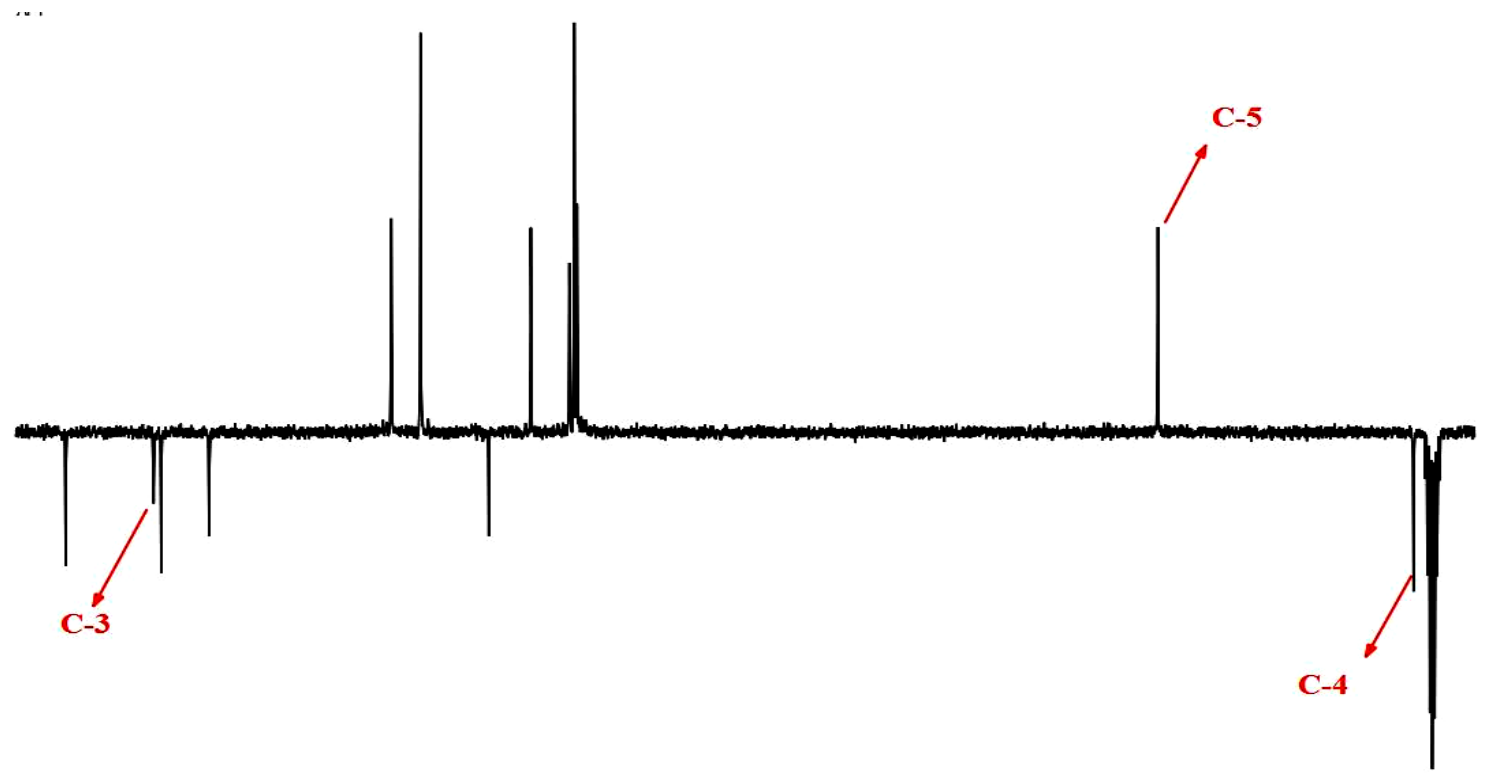

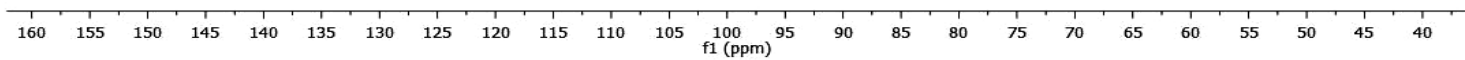

Şekil 6. 6 Nolu bileşiğin ${ }^{13}$ C-NMR (APT) spektrumu. 


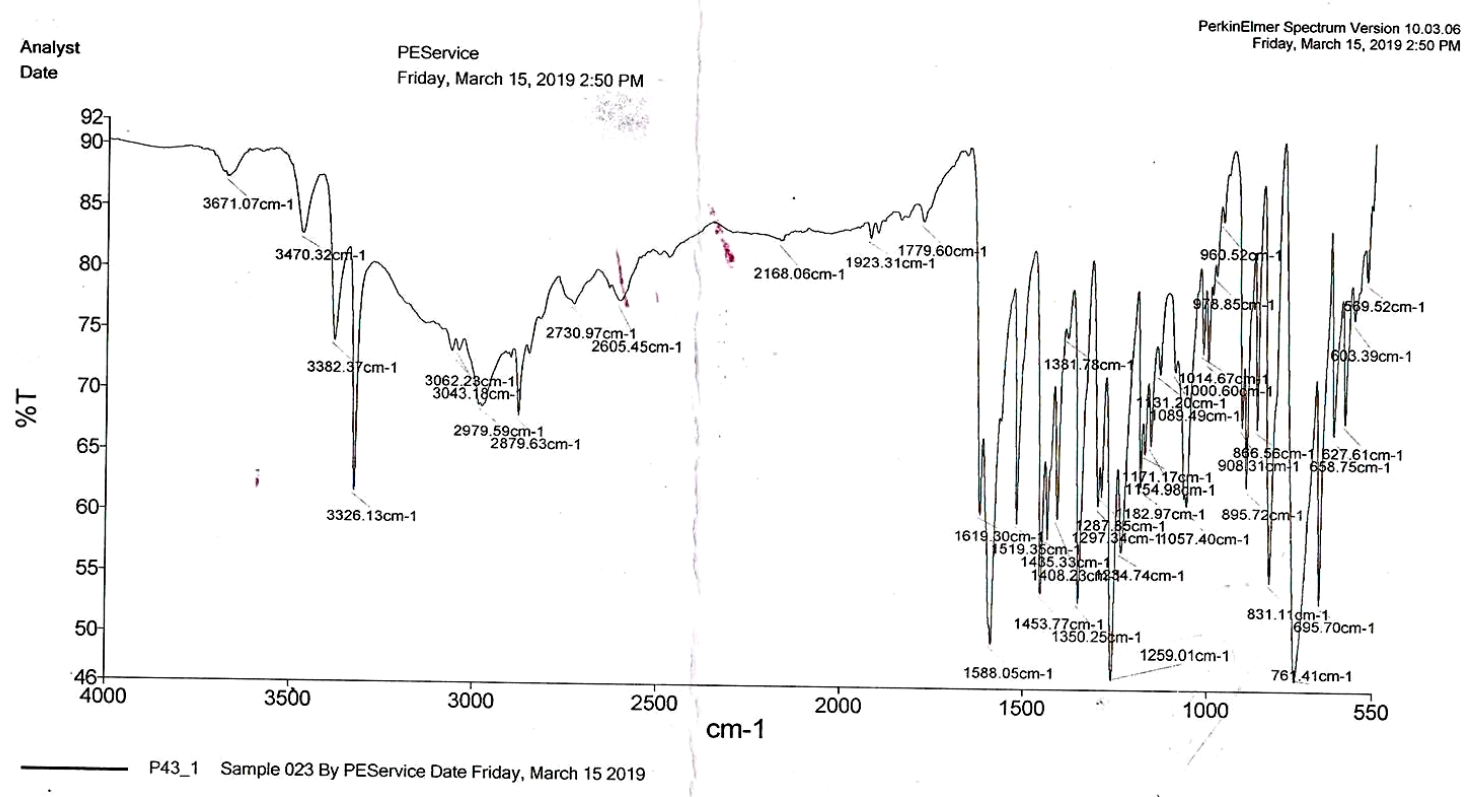

Şekil 7. 6 Nolu bileşiğin FT-IR spektrumu.

Çalışmanın ikinci kısmında ise bu bileşiklerin antioksidan ve enzim inhibisyonu özellikleri araştırılmıştır. Antioksidan aktivite tayininde DPPH radikal süpürme ve PRAP yöntemleri kullanılmıştır. Bu analizlere ait sonuçlar Tablo 2 ve Şekil 8'de verilmiştir.

Tablo 2. Bileşiklerin $125 \mu \mathrm{M}$ konsantrasyonda DPPH radikal süpürme aktivitesi fosfomolibdenyum indirgeyici güç aktivitesi (PRAP).

\begin{tabular}{ccc}
\hline Bileşik no & DPPH $(\boldsymbol{\%})$ & PRAP (Abs) \\
\hline $\mathbf{4}$ & $30.30 \pm 0.49$ & $0.597 \pm 0.006$ \\
$\mathbf{5}$ & $\mathbf{6 7 . 5 9} \pm \mathbf{0 . 4 4}$ & $\mathbf{0 . 8 1 5} \pm \mathbf{0 . 0 0 9}$ \\
$\mathbf{6}$ & $46.80 \pm 1.53$ & $0.468 \pm 0.008$ \\
Gallik asit & $85.27 \pm 0.07$ & - \\
Kuersetin & - & $0.714 \pm 0.002$ \\
\hline
\end{tabular}
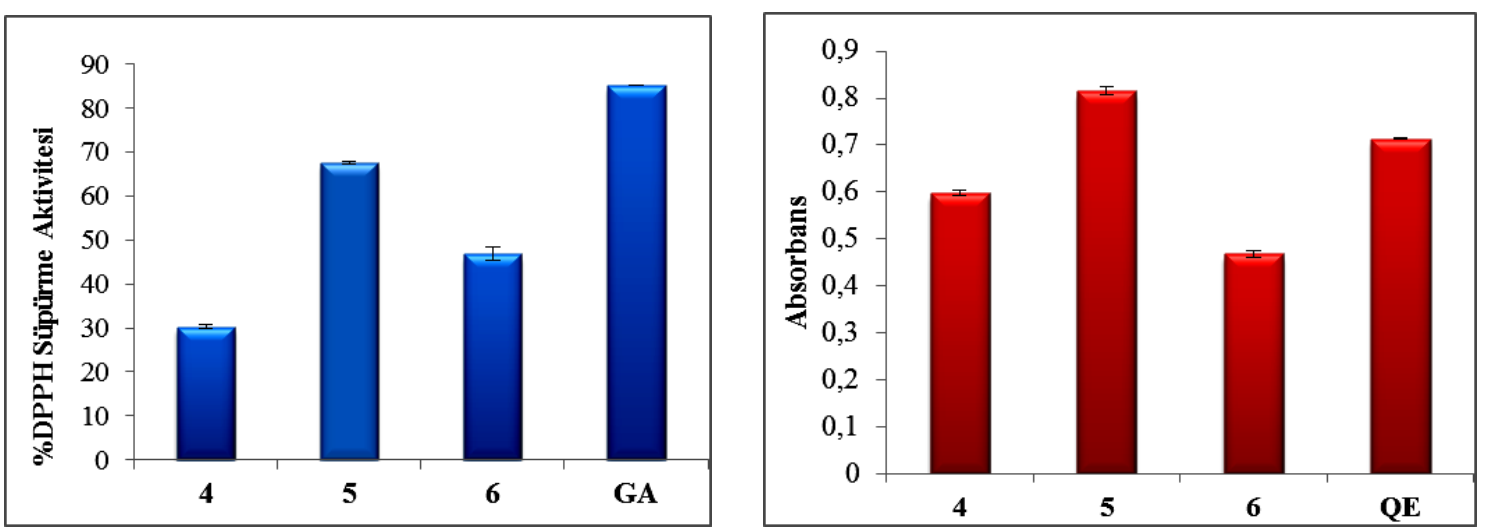

Şekil 8. Bileşiklerin $125 \mu \mathrm{M}$ konsantrasyonda DPPH radikal süpürme ve PRAP aktiviteleri. 
Bileşiklerin enzim inhibisyonu özelliklerinin belirlenmesinde ise tirosinaz ve $\alpha$ glikozidaz enzimlerini inhibisyonları araştırıldı. Bu analizlere ait sonuçlar Tablo 3'de verilmiştir.

Tablo 3. Bileşiklerin tirosinaz ve $\alpha$-glukozidaz enzimlerine karşı $\mathrm{IC}_{50}$ değerleri.

\begin{tabular}{ccc}
\hline Bileşik no & Tirozinaz $(\boldsymbol{\mu M})$ & o-glukozidaz $(\boldsymbol{\mu M})$ \\
\hline $\mathbf{4}$ & $\mathbf{1 6 . 6 8} \pm \mathbf{0 . 1 9}$ & $\mathbf{1 3 4 . 2 4} \pm \mathbf{2 . 5 1}$ \\
$\mathbf{5}$ & $154.41 \pm 3.41$ & $248.43 \pm 4.61$ \\
$\mathbf{6}$ & $22.60 \pm 0.83$ & $>250.00$ \\
Kojik asit & $35.41 \pm 0.19$ & - \\
Akarboz & - & $57.97 \pm 0.34$ \\
\hline
\end{tabular}

\section{Tartışma ve sonuçlar}

Çalışma kapsamında ilk olarak Claisen-Schmidt kondenzasyonu ile 3 adet kalkon bileşiği (1-3) [19, 29-30] ve bu bileşiklerin hidrazin hidratla asit katalizli Michael katılması reaksiyonuyla da moleküller arası halkalaşma ürünü olan 3 adet yeni 3,5disübstitüe-2-pirazolin türevi (4-6) sentezlenmiştir [31]. Elde edilen bileşiklerin yapıları FT-IR, ${ }^{1} \mathrm{H}-\mathrm{NMR},{ }^{13} \mathrm{C}-\mathrm{NMR}$ (APT) ve kütle spektral verileri kullanılarak aydınlatılmıştır. 3-6 Nolu bileşiklerin FT-IR spektrumları incelendiğinde yapıda sübstitüent olarak bulunan $\mathrm{O}-\mathrm{H}$ grubuna ait gerilmeler $3671 \mathrm{~cm}^{-1}$ ve $-\mathrm{NH}_{2}$ grubuna ait gerilmeler de 3384-3326 cm cm $^{-1}$ civarında keskin ikili band şeklinde görülmüştür. Pirazolin halka sisteminin varlığının en önemli kanıtı olan $\mathrm{N}-\mathrm{H}, \mathrm{C}=\mathrm{N}$ ve $\mathrm{C}-\mathrm{N}$ gerilme bantları ise sirasiyla $3471-3470,1634-1619$ ve $1256-1260 \mathrm{~cm}^{-1}$ aralıklarında beklenildiği şekilde görülmüştür. LC-MS/MS spektrumlarına bakıldığında ise $\mathrm{m} / \mathrm{z}$ değeri 253 olan moleküler iyon piki $\left([\mathrm{M}]^{+}\right)$temel pik olarak ortaya çıkmıştır. 4-6 Nolu bileşiklerin ${ }^{1} \mathrm{H}-\mathrm{NMR}$ spektrumları incelendiğnde $\delta 2.74-2.66 \mathrm{ppm}\left(\mathrm{C}_{4}-\mathrm{H}_{\mathrm{A}}\right)$ ve $\delta 3.35$ $3.26 \mathrm{ppm}\left(\mathrm{C}_{4}-\mathrm{H}_{\mathrm{B}}\right)$ aralıklarında dubletin dubleti $(\mathrm{dd})$ ve $\delta$ 4.62-4.64 ppm civarında triplet $(\mathrm{t})$ görünümlü kaynaşmış dubletin dubleti yarılmalar sırasıyla pirazolin halkasına ait geminal $-\mathrm{CH}_{2}-$ ve $-\mathrm{CH}-$ protonlarına aittir. $\mathrm{Bu}$ durum diastereotopik metilen ve metin protonlarının karakteristik özelliğidir ve metilenin (C-4) özdeş olmayan $\mathrm{H}_{\mathrm{A}}$ ve $\mathrm{H}_{B}$ protonları ile metinin (C-5) $\mathrm{H}_{\mathrm{X}}$ protonu arasında geminal-vicinal etkileşmeyle $\mathrm{ABX}$ spin sistemini oluşturmuştur (Şekil 9) [17, 31-32].

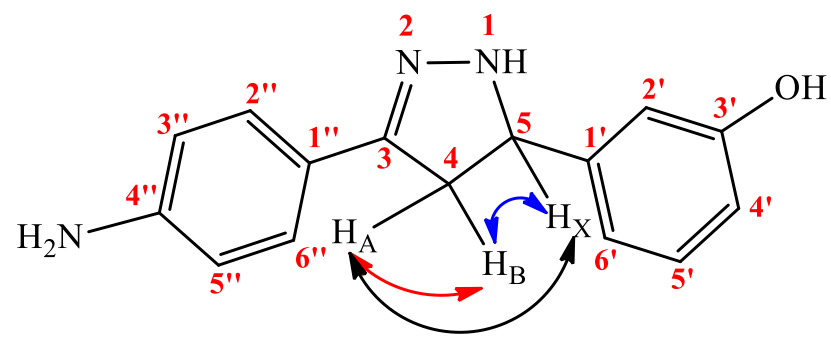

Şekil 9. Pirazolin halkasının ABX spin sistemi.

Bileşiklerin ${ }^{13} \mathrm{C}-\mathrm{NMR}$ (APT) spektrumları incelendiğinde $150 \mathrm{ppm}$ civarında çıkan kuaternerik pik halkalaşma sonucu oluşan $\mathrm{C}_{3}$ karbonuna ait olup yine $41 \mathrm{ppm}$ civarındaki $-\mathrm{CH}_{2}-$ ile $63 \mathrm{ppm}$ civarındaki $-\mathrm{CH}$ - pikleri pirazolin halkasının en belirgin kanıtları olup yapıyı desteklemektedir. Yine başlangıç bileşikleri olan kalkonların 190 
ppm civarında rezoanansa gelen karbonil karbonuna ait pikin kaybolması da yapıyı destekleyen bir başka spektral veridir. Bütün bu spektroskopik sonuçlar yapıların önerildiği şekilde olduğunu doğrulamaktadır. Sentezlenen 4-6 nolu bileşiklere literatürde rastlanmamış olup, bu çalışmayla potansiyel biyoaktif bileşik türevleri sentezlenmiştir. Bileşiklerin NMR spektrumları DMSO'da çözünürlükleri iyi olduğu için DMSO-d $\mathrm{d}_{6}$ 'da alınmış olup ${ }^{13} \mathrm{C}$ - NMR spektrumları net olmasına rağmen, bu çözücüde ${ }^{1} \mathrm{H}-\mathrm{NMR}$ 'da beklenen sinyal yarılmaları net bir şekilde görülememiştir. $\mathrm{Bu}$ sebeple ${ }^{1} \mathrm{H}-\mathrm{NMR}$ spektrumları $\mathrm{CD}_{3} \mathrm{OD} / \mathrm{DMSO}-\mathrm{d}_{6}$ çözücü karışımında alınmış ve sinyal yarılmaları net bir şekilde görülmüştür. Bunun yanında molekül yapısında bulunan ve döteryum değişimine uğrayabilecek $-\mathrm{OH}$, $-\mathrm{NH}$ ve $-\mathrm{NH}_{2}$ protonları $\mathrm{CD}_{3} \mathrm{OD}$ 'den dolayı döteryum değişimine uğramış ve bunlara ait sinyaller spektrumda görülememiştir. $\mathrm{Bu}$ grupların varlığı ise FT-IR spektrumları ile desteklenmiştir.

Çalışmanın ikinci kısmında, pirazolinlerin sahip oldukları biyolojik ve farmakolojik özelliklerden yola çıkarak, sentezlenen yeni türevlerinde DPPH radikal süpürme ve fosfomolibdenyum indirgeyici güç (PRAP) aktiviteleri ile tirozinaz ve $\alpha$-glikozidaz enzim inhibisyon aktiviteleri araştırılmıştır. Elde edilen sonuçlar doğrultusunda DPPH ve PRAP çalışmalarında 5 nolu bileşik125 $\mu \mathrm{M}$ konsantrasyonda sırasıyla \% $67.59 \pm$ 0.44 süpürme aktivitesi ve $0.815 \pm \mathbf{0 . 0 0 9}$ absorbans göstererek üç bileşik arasında en yüksek DPPH radikal süpürme ve PRAP aktivitesiyle en iyi antioksidan olduğunu göstermiştir. Bileşiklerin yapı-antioksidan aktivite ilişkileri kalitatif olarak tartışıldığında her üç bileşik yapısını farklılandıran $-\mathrm{NH}_{2}$ grubunun pozisyonu olup meta- pozisyonunda en yüksek aktivite sergilenmiştir. Bileşiklerin tirozinaz ve $\alpha$ glukozidaz enzim inhibisyonu çalışmalarıdan elde edilen veriler doğrultusunda ise; 4 nolu bileşiğin $16.68 \pm 0.19 \mu \mathrm{M}$ ve 6 nolu bileşiğin $22.60 \pm \mathbf{0 . 8 3} \mu \mathrm{M} \mathrm{IC}_{50}$ değerleriyle standart kojik asitten $\left(\mathrm{IC}_{50}=\mathbf{3 5 . 4 1} \pm \mathbf{0 . 1 9} \mu \mathrm{M}\right)$ daha iyi tirozinaz inhibitörleri olduklar1 belirlenmiştir. Bileşiklerin $\alpha$-glukozidaz enzim inhibisyon aktiviteleri çok yüksek olmamakla birlikte 4 nolu bileşik en yüksek aktiviteyi $\left(\mathrm{IC}_{50}=\mathbf{1 3 4 . 2 4} \pm \mathbf{2 . 5 1} \mu \mathrm{M}\right)$ göstermiştir. Yapı-enzim inhibisyonu aktivitesi genel olarak tartışıldığında ise $-\mathrm{NH}_{2}$ grubunun - orto pozisyonda oluşu enzim inhibisyonunu artırmıştır. Sentezlenen 4-6 nolu bileşiklere literatürde rastlanmamış olup, bu çalışmayla potansiyel biyoaktif pirazolin türevleri sentezlenmiştir.

\section{Teşekkür}

Yapılan çalışmada biyolojik aktivite testlerindeki katkılarından dolayı Arş. Gör. Burak BARUT'a teşekkür ederim.

\section{Kaynaklar}

[1] Aliyazıcıoğlu, R., Akkaya, Ş., Korkmaz, N., Şener, S. Ö., Badem, M., Özgen, U. ve Alpay Karaoğlu, Ş., Onobrychis oxyodonta'nın topraküstü kısmında antioksidan, antimikrobiyal ve tirozinaz inhibitör, Fırat Üniversitesi Sağlık Bilimleri Tıp Dergisi, 31, 1, 25-31, (2017).

[2] Qin, H. L., Shang Z. P., Jantan, I., Unsal Tan, O., Hussain M. A., Sher, M., Bukhari ve S. N. Abbas., Molecular docking studies and biological evaluation of chalcone based pyrazolines as tyrosinase inhibitors and potential anticancer agents, RSC Advances, 5, 46330-46338, (2015). 
[3] Cui, H. X., Duan, F. F., Jia, S. S., Cheng, F. R. ve Yuan, K., Antioxidant and tyrosinase inhibitory activities of seed oils from Torreya grandis Fort. ex Lindl., BioMed Research International, 2018, 10 pages, (2018).

[4] Chang, T.S., An updated review of tyrosinase inhibitors, International Journal of Molecular Sciences, 10, 2440-2475, (2009).

[5] Turan, E. ve Kulaksızoğlu, M., Tip 2 diyabet tedavisinde güncel yaklaşımlar, Okmeydanı Tıp Dergisi, 31(Ek sayı), 86-94, (2015).

[6] Yousefi, R., Alavian-Mehr, M. M., Mokhtari, F., Panahi, F., Mehraban, M.H. ve Khalafi-Nezhad, A., Pyrimidine-fused heterocycle derivatives as a novel class of inhibitors for $\alpha$-glucosidase, Journal of Enzyme Inhibition and Medicinal Chemistry, 28, 6, 1228-1235, (2013).

[7] Elya, B., Basah, K., Mun'im A., Yuliastuti, W., Bangun, A. ve Septiana E. K., Screening of $\alpha$-glucosidase inhibitory activity from some plants of Apocynaceae, Clusiaceae, Euphorbiaceae, and Rubiaceae, Journal of Biomedicine and Biotechnology, 2012, 6 pages, (2012).

[8] Colotta ,V., Catarzi, D., Varano, F., Filacchioni, G. ve Cecchi, L., Synthesis and binding activity of some pyrazolo[1,5-c]quinazolines as tools to verify and optional binding site of a benzodiazepine receptor ligand, Journal of Medicinal Chemistry, 39, 2915-2921, (1996).

[9] Patel, M.R., Dodiya, B.L., Ghetiya, R.M., Joshi, K.A., Vekariya, P.B., Bapodara, A.H. ve Joshi, H.S., Synthesis and antimicrobial evaluation of pyrazoline derivatives, International Journal of ChemTech Research, 3, 2, 967-974, (2011).

[10] Pinto, D.C.G.A., Silva, A.M.S., Cavaleiro, J.A.S. ve Elguero, J., New bis(chalcones) and their transformation into bis(pyrazoline) and bis(pyrazole) derivatives, European Journal of Organic Chemistry, 4, 747-755, (2003).

[11] Rostom, S.A.F, Badr, M.H., Abd El Razik, H.A., Ashour, H.M.A., ve Abdel Wahab, A.E., Synthesis of some pyrazolines and pyrimidines derived from polymethoxy chalcones as anticancer and antimicrobial agents, Archiv der Pharmazie-Chemistry in Life Sciences, 344, 572-587, (2011).

[12] Marella, A., Ali, M. R., Alam, M. T., Saha, R., Tanwar, O., Akhter, M., Shaquiquzzaman, M. ve Alam M. M., Pyrazolines: A biological review, Mini Reviews in Medicinal Chemistry, 13, 6, 921-931, (2013).

[13] Yusuf, M. ve Jain, P., Synthetic and biological studies of pyrazolines and related heterocyclic compounds, Arabian Journal of Chemistry, 7, 553-596, (2014).

[14] Tanwer, N., Kaur, R., Rana, D., Singh, R. ve Singh, K., Synthesis and characterization of pyrazoline derivatives, Journal of Integrated Science \& Technology, 3, 2, 39-41, (2015).

[15] Bano, S., Alam, M. S., Javed, K., Dudeja, M., Das, A. K. ve Dhulap, A., Synthesis, biological evaluation and molecular docking of some substituted pyrazolines and isoxazolines as potential antimicrobial agents, European Journal of Medicinal Chemistry, 95, 96-103, (2015).

[16] Amin, K. M., Eissa, A. A. M., Abou-Seri, S. M., Awadallah, F. M. ve Hassan G. S., Synthesis and biological evaluation of novel coumarinepyrazoline hybrids endowed with phenylsulfonyl moiety as antitumor agents, European Journal of Medicinal Chemistry, 60, 187-198, (2013).

[17] Karabacak, M., Altıntop, M. D., Çiftçi, H. İ., Koga, R., Otsuka, M., Fujita, M., ve Özdemir, A., Synthesis and evaluation of new pyrazoline derivatives as potential anticancer agents, Molecules, 20, 19066-19084, (2015). 
[18] George, R. F., Fouad, M. A. ve Gomaa, I. E.O., Synthesis and cytotoxic activities of some pyrazoline derivatives bearing phenyl pyridazine core as new apoptosis inducers, European Journal of Medicinal Chemistry, 112, 48-59, (2016).

[19] Viveka, S., Dinesha, Shama, P., Nagaraja, G. K., Ballav, S. ve Kerkar, S., Design and synthesis of some new pyrazolyl-pyrazolines as potential antiinflammatory, analgesic and antibacterial agents, European Journal of Medicinal Chemistry, 101, 442-451, (2015).

[20] He, J., Ma, L.,Wei, Z., Zhu, J., Peng, F., Shao, M., Lei, L.,He, L. ve Tang, M., Synthesis and biological evaluation of novel pyrazoline derivatives as potent anti-inflammatory agents, Bioorganic \& Medicinal Chemistry Letters, 25, 2429-2433, (2015).

[21] Mallikarjuna Rao, R., Sreeramulu, J., Ravindranath, L. K., Nagaraja Reddy, G., Hanumanthurayudu, K., Nageswara Reddy, G., Jayaraju, A. ve Madhusudhan, P., Synthesis and biological screening of some pyridine and pyrrole derivatives of pyrazolo [3,4-c] pyrazoles, Journal of Chemical and Pharmaceutical Research, 4, 1, 272-278, (2012).

[22] Ahmad, P., Woob, H., Jun, K. Y., Kadi, A. A., Abdel-Aziz, H. A., Kwon, Y. ve Motiur Rahman, A. F. M., Design, synthesis, topoisomerase I \& II inhibitory activity, antiproliferative activity, and structure-activity relationship study of pyrazoline derivatives: An ATP-competitive human topoisomerase II $\alpha$ catalytic inhibitör, Bioorganic \& Medicinal Chemistry, 24, 1898-1908, (2016).

[23] Saeed, A., Mahesar, P. A., Channar, P. A., Abbas, Q., Larik, F. A., Hassan, M., Raza, H. ve Seo, S. Y., Synthesis, molecular docking studies of coumarinylpyrazolinyl substituted thiazoles as non-competitive inhibitors of mushroom tyrosinase, Bioorganic Chemistry, 74, 187-196, (2017).

[24] Bardalai, D. ve Panneerselvam, P., Pyrazole and pyrazoline derivatives: potential anti-inflammatory and analgesic agents, International Research Journal of Pharmaceutical and Applied Sciences, 2, 3, 1-8, (2012).

[25] Blois, M. S., Antioxidant determinations by the use of a stable free radical, Nature, 29, 1199-1200, (1958).

[26] Falcioni, G., Fedeli, D., Diano, L., Calzuola, I., Mancinelli, L., Marsili, V. ve Gianfranceschi, G., Antioxidant activity of wheat sprouts extract in vitro: inhibition of DNA oxidative damage, Journal of Food Science, 67, 2918-2922, (2002).

[27] Masuda, T., Yamashita, D., Takeda, Y. ve Yonemori, S., Screening for tyrosinase inhibitors among extracts of seashore plants and identification of potent inhibitors from Garcinia subelliptica, Boscience, Biotechnology, Biochemistry, 69, 197-201, (2005).

[28] Şöhretoğlu, D., Sari, S., Özel, A. ve Barut, B., $\alpha$-Glucosidase inhibitory effect of Potentilla astracanica and someisoflavones: Inhibition kinetics and mechanistic insights through in vitro and in silico studies, International Journal of Biological Macromolecules, 105, 1062-1070, (2017).

[29] Kahriman, N., Yılmaz İskender, N., Yücel, M., Yaylı, N., Demir, E. ve Demirbağ Z., Microwave assisted synthesis of 1,3'-diazaflavanone/flavones and their alkyl derivatives with antimicrobial activity, Journal of Heterocyclic Chemistry, 49, 1, 71-79, (2012).

[30] Kahriman, N., Yaylı, B., Aktaş, A., İskefiyeli, Z., Beriş, F.Ş. ve Yaylı N., Synthesis, antibacterial and antioxidant activities of new 1-Alkyl-4-(1-alkyl-4- 
oxo-1,4-dihydroquinolin-2-yl)pyridinium bromides, European Journal of Medicinal Chemistry, 69, 348-355, (2013).

[31] Kahriman, N., Şenyürek, Z., Serdaroğlu, V., Beriş, F.Ş., Barut, B. ve Yayli, N., Synthesis of novel pyrazolines, their boron-fluorine complexes, and investigation of antibacterial, antioxidant, and enzyme inhibition activities, Archiv Der Pharmazie, 350, 2, 1-12, (2017).

[32] Salgın Gökşen, U., Bazı yeni 2-pirazolin türevlerinin sentezi ve monoamin oksidaz (MAO) inhibitör aktiviteleri üzerinde çalışmalar, Doktora Tezi, Hacettepe Üniversitesi, Sağl1k Bilimleri Enstitüsü, Ankara, (2015). 